\title{
Transcription factor CCAAT/enhancer binding protein alpha up-regulates microRNA let-7a-1 in lung cancer cells by direct binding
}

\author{
Yani Lin ${ }^{1 \dagger}$, Jian Zhao ${ }^{2 \dagger}$, Xiaoyan Hu${ }^{1}$, Lina Wang ${ }^{1}$, Liming Liang ${ }^{1}$ and Weiwen Chen ${ }^{1 *}$
}

\begin{abstract}
Aims: The transcription factor CCAAT/enhancer binding protein a (C/EBPa) and microRNA (miRNA) let-7a-1 act as tumor suppressors in many types of cancers including lung cancer. In the present study, we aim to investigate whether let-7a-1 is a novel important target of C/EBPa in lung cancer cells.
\end{abstract}

Methods: The DNA sequence of the 2.1 kb let-7a-1 promoter was analyzed with MatInspector 4.1 (http://www.genomatix.de). Human lung cancer cell lines A549 and H1299, and human cervical cancer cell line Hela were used for transfection. Total RNA was extracted from cells using Trizol reagent and pri-let-7a-1 mRNA expression was measured using quantitative real-time polymerase chain reaction. Western blotting was performed to detect C/EBPa protein expression. To test whether C/EBP-a could up-regulate the expression level of let-7a at transcription level, dual-luciferase reporter gene assay was carried out. To determine whether C/EBPa could bind let-7a-1 promoter, electrophoretic mobility shift assay was employed. To further confirm the direct targeting let-7a-1 promoter by C/EBPa, chromatin immunoprecipitation was used.

Results: Both C/EBPa and let-7a-1 were down-regulated in lung cancer A549 and H1299 cells, but up-regulated in Hela cells. Transfection and reporter gene assay showed that C/EBPa increased the expression of let-7a-1 at transcription level. Bioinformatics assay identified four putative C/EBP elements within let-7a-1 promoter. Dual-luciferase reporter gene, electrophoretic mobility shift assay and chromatin immunoprecipitation assays demonstrated that these four elements mediated the up-regulation effect of C/EBPa on let-7a-1.

Conclusions: The present study reveals that decreased C/EBPa contributes to the down-regulation of miRNA let-7a-1 in lung cancer cells.

Keywords: C/EBPa, let-7a-1, Promoter, Lung cancer

\section{Background}

MicroRNA (miRNA) let-7 family plays pivotal roles in regulating carcinogenesis [1]. The let-7 family functions as tumor suppressors in multiple tumor types. They can inhibit the expressions of multiple oncogenes, including rat sarcoma viral oncogene homolog (RAS), high mobility group AT-hook 2 (HMGA2) and v-myc avian myelocytomatosis viral oncogene homolog (MYC) [2-4].

\footnotetext{
*Correspondence: chenweiwen@sdu.edu.cn

†Yani Lin and Jian Zhao contributed equally to this work

${ }^{1}$ Department of Biochemistry and Molecular Biology, School of Medicine,

Shandong University, Jinan 250012, People's Republic of China

Full list of author information is available at the end of the article
}

Down-regulation of let-7 family members is observed in multiple carcinomas, especially in lung cancer [5-7]. Therefore, the mechanism of down-regulation of let-7 family members in various cancers needs to be elucidated, and will help understand the regulation mechanism of let-7 in carcinogenesis.

Humans have 13 let-7 family members [8], including let-7a-1, let-7a-2, let-7a-3, let-7b, let-7c, let-7d, let7e, let-7f-1, let-7f-2, let-7g, let-7i, miR-98, and miR-202, which are located in nine different loci on chromosomes $3,9-12,19,21,22$, and X. A total of ten mature let7 -family sequences are produced from the 13 precursor sequences. For example, pre-let-7a-1, pre-let-7a-2 and 
pre-let-7a-3 produce mature let-7a, while pre-let-7f-1 and pre-let-7a-2 produce mature let- $7 \mathrm{f}$. At transcriptional level, it has been reported that let-7 family members can be inhibited by oncogenic transcription factor MYC in lymphoma and hepatocellular carcinoma cells $[9,10]$. It is also shown that transcriptional repressor jumonji ATrich interactive domain 1B (JARID1B) protein binds to let-7e promoter, leading to the repression of let-7e and the promotion of breast tumor cell cycle [11]. In addition, nuclear factor-kappa B (NF-kB) can enhance the transcription of let-7a-3/let-7b cluster in Hela cells [12]. At posttranscriptional level, the main regulation factor for let- 7 family members is lin 28 , which blocks the maturation of pri-let-7 by binding the loop region of the pri-let-7 stem-loop [13, 14]. However, the understanding about the regulation of let-7 is still limited. Three let-7 family members, let-7a-1, let-7f- 1 and let-7d-1, form an intergenic miRNA cluster on chromosome 9p22.32, which is encoded by a single polycistronic transcript driven by a single promoter. The three members are the most abundant species of let-7 family, together accounting for about $24 \%$ of all let- 7 precursors $[5,15]$. In addition, let-7a- 1 is reported to be down-regulated in lung cancer, suppressing the proliferation of lung cancer cells by its overexpression $[3,5]$.

The CCAAT/enhancer binding protein $\alpha(\mathrm{C} / \mathrm{EBP} \alpha)$ is a differentiation-inducing transcription factor that belongs to a family of basic region leucine zipper (bZIP) transcription factors, which includes six members $(\alpha, \beta$, $\gamma, \delta, \varepsilon$ and $\zeta)$ [16]. C/EBP $\alpha$ is required for proper control of adipogenesis, glucose metabolism, granulocytic differentiation, and lung development. Many studies demonstrate that C/EBPa indeed acts as a tumor suppressor in a number of tumor types [17]. In order to better understand the regulation of let-7a-1 in lung cancer cells, we cloned a $2.1 \mathrm{~kb}$ promoter fragment of let-7a-1 and made the preliminary analysis on its function in our previous work [18]. Our previous study shows that C/EBP $\alpha$ enhances the promoter activity of let-7a-1 [18]. Although a growing number of studies have demonstrated the regulation of specific miRNAs by C/EBP $\alpha$ [19-25], it is still unknown whether let-7 is the target of C/EBP $\alpha$. In the present study, we investigate the influence of the C/EBP $\alpha$ on let-7a-1 regulation in lung cancer cells.

\section{Methods}

\section{Bioinformatics}

The DNA sequence of the $2.1 \mathrm{~kb}$ let-7a-1 promoter was analyzed with MatInspector 4.1 (http://www.genomatix. de). The MatInspector 4.1 software identifies putative transcription factor binding sites with weight matrices representing consensus recognition sequences for different transcription factors as defined in the MatInspector library [26]. Four CCAAT/enhancer binding protein sites upstream of the let-7a-1 start site were identified. They were termed CEBP1-4 in this work, respectively.

\section{Cells}

Human lung cancer cell lines A549 and H1299, and human cervical cancer cell line Hela were obtained from Shanghai Institute of Biochemistry and Cell Biology, Chinese Academy of Science (Shanghai, China) and maintained in RPMI1640, F-12 K and DMEM (GIBCO, Thermo Fisher Scientific, Waltham, MA, USA) medium, respectively, supplemented with $10 \%$ fetal bovine serum (FBS; GIBCO, Thermo Fisher Scientific, Waltham, MA, USA), in a humidified atmosphere with $5 \% \mathrm{CO}_{2}$ at $37^{\circ} \mathrm{C}$. Within $24 \mathrm{~h}$ of passage, all cells with more than $90 \%$ confluence were used for transfection. X-tremeGENE HP (Roche, Mannheim, Germany) or Lipofectamin 2000 Transfection Agent (Thermo Fisher Scientific, Waltham, MA, USA) was used for plasmid or siRNA transfection, respectively, according to the manufacturer's instructions.

\section{Plasmids}

A 2.1-kb let-7a-1 promoter was cut from pGL3-2123 that was constructed in our previous work [18], and cloned into pGL4.10 [luc2] vector (Promega, Fitchburg, WI, USA) between Xho I and Hind III sites to form pGL4.102123. Four wild-type and mutant CEBP elements as well as CEBP consensus sequences were synthesized (Table 1). The double-stranded sequences were generated by annealing equal amounts of sense and antisense sequences at $95^{\circ} \mathrm{C}$ for $10 \mathrm{~min}$, and then cooling to room temperature. The double-stranded sequences with overhanging Xho I (tcgag) and Hind III (agctt) sites were inserted into the $5^{\prime}$ end of the luciferase gene in pGL4.23 [luc $2 / \mathrm{minP}]$ vector to generate pGL4.23-CEBP $1-4 \mathrm{w} / \mathrm{m}$, respectively. In the same way, the target sequence of let7a (5'-UGAGGUAGUAGGUUGUAUAGUU-3') was synthesized and inserted into sac I and Hind III sites of pMIR-Report luciferase reporter vector (Ambion, Thermo Fisher Scientific, Waltham, MA, USA) to generate pMIR-let7aT plasmid. All of the constructs were confirmed by DNA sequencing.

\section{Small interfering RNA (siRNA)}

To knock down the expression of C/EBP $\alpha$, Hela cells were transfected with si-h-C/EBP $\alpha-002$ (RiboBio, Guangzhou, China) using Lipofectamine 2000 (Invitrogen, Thermo Fisher Scientific, Waltham, MA, USA). Nontargeting control siRNA (RiboBio, Guangzhou, China) and transfection reagents only (mock transfection) were transfected as negative controls. The siRNA was diluted to $50 \mathrm{nM}$ in Opti-MEM I reduced-serum medium 
Table 1 Oligonucleotide sequences used for reporter gene assay

\begin{tabular}{|c|c|}
\hline Name & Sequences $\left(5^{\prime}-3^{\prime}\right)$ \\
\hline CEBP consensus wild-type (CEBPcw) & Sense, tcgagTGCAGATTGCGCAATCTGCAa; anti-sense, agcttTGCAGATTGCGCAATCTGCAC \\
\hline CEBP consensus mutant (CEBPcm) & Sense, tcgagTGCAGAGACTAGTCTCTGCAa; anti-sense, gcttTGCAGAGACTAGTCTCTGCAC \\
\hline CEBP consensus wild-type (CEBP1w) & Sense, tcgagGAGGTTGTGAAACCCa; anti-sense, agcttGGGTTTCACAACCTCc \\
\hline CEBP consensus mutant (CEBP1 m) & Sense, tcgagGAGGGAGTAAGCCCC $a$; anti-sense, agcttGGGTTTCACAACCTCc \\
\hline CEBP2 wild-type (CEBP2w) & Sense, tcgagTGTGTTCTGTAAGCC $a$; anti-sense, agcttGGCTTACAGAACACAc \\
\hline CEBP2 mutant (CEBP2 m) & Sense, tcgagTGTGGTCTATGCGCC $a$; anti-sense, agcttGGCGCATAGACCACAC \\
\hline CEBP3 wild-type (CEBP3w) & Sense, tcgagTACGTTTTGTAATTTa; anti-sense, agcttAAATTACAAAACGTA $\underline{c}$ \\
\hline CEBP3 mutant (CEBP3 m) & Sense, tcgagTACGGTTTATGCTTTa; anti-sense, agcttAAAGCATAAACCGTAc \\
\hline CEBP4 wild-type (CEBP4w) & Sense, tcgagAAGATTCAGAAATCAa; anti-sense, agcttTGATTTCTGAATCTTc \\
\hline CEBP4 mutant (CEBP4 m) & Sense, tcgagAAGAGTCAAAGCTCAa; anti-sense, agcttTGAGCTTTGACTCTTc \\
\hline
\end{tabular}

(Invitrogen, Thermo Fisher Scientific, Waltham, MA, USA). After transfection for $48 \mathrm{~h}$, cells were collected to confirm the effect of $\mathrm{C} / \mathrm{EBP} \alpha$ knockdown at both mRNA expression levels and protein expression levels.

\section{Quantitative reverse-transcription polymerase chain reaction (qRT-PCR)}

Total RNA was extracted from cells using Trizol reagent (Invitrogen, Thermo Fisher Scientific, Waltham, MA, USA) according to the manufacturer's instructions. First strand cDNA was synthesized using a Revert Aid First Strand cDNA Synthesis Kit (Fermentas, Thermo Fisher Scientific, Waltham, MA, USA). The qRT-PCR amplification of pri-let-7a-1 was performed according to a previous method [5].

\section{Western blotting}

Western blotting was performed to detect $\mathrm{C} / \mathrm{EBP} \alpha$ protein expression. Whole-cell lysates were prepared using lysis buffer [containing $50 \mathrm{mmol} / \mathrm{L}$ Tris- $\mathrm{Cl}(\mathrm{pH} 8.0)$, $150 \mathrm{mmol} / \mathrm{L} \mathrm{NaCl}, 0.1 \% \mathrm{SDS}, 1 \% \mathrm{NP}-40$ and $100 \mathrm{mg} /$ $\mathrm{ml}$ PMSF]. Protein concentration was determined using Bradford assay (Bio-Rad, Hercules, CA, USA). Extracted protein $(30 \mu \mathrm{g})$ was processed in a $10 \%$ SDS-PAGE gel and transferred to a polyvinylidene fluoride membrane. Protein levels of $\mathrm{C} / \mathrm{EBP} \alpha$ were measured by antibody raised against the $\mathrm{C}$-terminus of human $\mathrm{C} / \mathrm{EBP} \alpha$ (sc9314X, Santa Cruz Biotechnology, Dallas, TX, USA). Anti- $\beta$-Actin (Sigma, St. Louis, MO, USA) was used as an internal control. Immunoblots were detected using an enhanced chemiluminescence kit (Santa Cruz Biotechnology, Dallas, TX, USA) and visualized after exposure to $\mathrm{X}$-ray film.

\section{Dual-luciferase reporter gene assay}

Cells in 70-80 \% confluence were co-transfected in 24 -well plates. Each well contained $0.3 \mu \mathrm{g}$ reporter gene plasmid, $0.02 \mu \mathrm{g}$ of the internal control vector pGL4.74 [hRluc/TK] vector (Promega, Fitchburg, WI, USA), $1 \mu \mathrm{l}$ transfection agent, and $0.2 \mu \mathrm{g}$ expression vector or si-RNA. At $48 \mathrm{~h}$ after the completion of the transfection procedure, all the cells underwent dual-luciferase reporter assay, following the protocol recommended by the manufacturer's manual. The cells were lysed using $1 \times$ reporter lysis buffer and harvested by manual scraping. Luminescence was detected using a Mithras LB 940 (Berthold Technologies, Oak Ridge, TN, USA). The firefly luciferase activity of the reporter gene plasmid was measure 1 (M1), and the renilla luciferase activity (internal control) of pGL4.74 [hRluc/TK] vector was measure 2 (M2). The relative luciferase activity was calculated as the ratio of $\mathrm{M} 1 / \mathrm{M} 2$.

\section{Electrophoretic mobility shift assay (EMSA)}

At $24 \mathrm{~h}$ before transfection, $\mathrm{H} 1299$ cells were inoculated in 6-well plate. When in 70-80\% confluence, each well was transfected by $0.2 \mu \mathrm{g}$ pcDNA3.1(+)-C/EBP $\alpha$. At $48 \mathrm{~h}$ after transfection, the cells were collected and prepared for nuclear extracts as described previously [27]. Double-stranded oligonucleotide probes were obtained by annealing sense and antisense sequences (Table 2). Probes were end-labeled with digoxin using T4 polynucleotide kinase (Invitrogen, Thermo Fisher Scientific,

Table 2 Oligonucleotide sequences used for electrophoretic mobility shift assay

\begin{tabular}{ll}
\hline Name & Sequences \\
\hline CEBP consensus & 5'-TGCAGATTGCGCAATCTGCA-3' \\
CEBP1 $(-1726 /-1712)$ & $5^{\prime}$-gaaGAGGTTGTGAAACCCcct-3' \\
CEBP2 $(-1684 /-1670)$ & $5^{\prime}$-tccTGTGTTCTGTAAGCCatc-3' \\
CEBP3 $(-722 /-708)$ & $5^{\prime}$-tatTACGTTTTGTAATTTtaa-3' \\
CEBP4 $(-163 /-149)$ & $5^{\prime}$-tacAAGATTCAGAAATCAccc-3' \\
\hline
\end{tabular}


Waltham, MA, USA). EMSA was performed using the DIG Gel Shift Kit (Second Generation; Roche, Basel, Switzerland) following the manufacturer's protocol. Antibodies against C/EBP $\alpha$ (sc-9314x; Santa Cruz Biotechnology, Dallas, TX, USA) was used for supershift assay.

\section{Chromatin immunoprecipitation (ChIP)}

At $24 \mathrm{~h}$ before transfection, $\mathrm{H} 1299$ cells were inoculated in $10-\mathrm{cm}$ dishes. When in 70-80\% confluence, each well was transfected by $2 \mu \mathrm{g}$ pcDNA3.1(+)-C/EBP $\alpha$ or pcDNA3.1(+). At $48 \mathrm{~h}$ after transfection, the cells were collected and ChIP assay was performed using ChIP Assay Kit (Millippore, Billerica, MA, USA) following the manufacturer's protocol. For each immunoprecipitation reaction, $10^{6} \mathrm{H} 1299$ cells and $2 \mu \mathrm{g}$ of goat anti-C/ EBPa (sc-9314x; Santa Cruz Biotechnology, Dallas, TX, USA) or control IgG (Santa Cruz Biotechnology, Dallas, TX, USA) were used. The immunoprecipitated DNA was recovered and used as template for PCR using three pairs of primers complementary to the region flanking the $\mathrm{C} / \mathrm{EBP} \alpha$ motifs in let-7a-1 promoter (Table 3 ). The products were resolved on agarose gel, purified and sequenced. An aliquot of sheared chromatin DNA was subjected to PCR before immunoprecipitation and served as input control.

\section{Statistical analysis}

All data were analyzed using SPSS 17.0 software package (IBM, Armonk, NY, USA). All values were expressed as mean \pm standard deviation from at least three independent experiments. Statistical significance was defined as $\mathrm{P}<0.05$.

\section{Results}

Positive correlation may exist between the expression levels of C/EBPa and pri-let-7a-1

To determine the expression levels of C/EBP $\alpha$ and prilet-7a-1, western blotting and qRT-PCR were used, respectively. The data showed that $\mathrm{C} / \mathrm{EBP} \alpha$ and pri-let7a-1 levels in A549 cells were significantly higher than that in H1299 cells, but were significantly lower than that in Hela cells (Fig. 1a, b). The result suggests that positive correlation may exist between the expression levels of $\mathrm{C} /$ $\mathrm{EBP} \alpha$ and pri-let-7a-1.
C/EBPa expression affects the promoter activity of let-7a-1 in a dose-dependent manner

To study how C/EBP $\alpha$ expression affects the promoter activity of let-7a-1, we performed reporter gene assay. The data showed that ectopic $\mathrm{C} / \mathrm{EBP} \alpha$ expression increased the promoter activity of let-7a-1 significantly in H1299 cells in a dose-dependent manner, reaching the maximal 5.11-fold at $0.05 \mu \mathrm{g}$ vector transfection After that, the effect was weaken as the continued increase of transfection doses (Fig. 2). This result indicates that $\mathrm{C} /$ EBP $\alpha$ expression affects the promoter activity of let-7a-1 in a dose-dependent manner.

\section{C/EBP- $a$ up-regulates the expression level of let-7a at transcription level}

To further investigate whether the expression of let7a-1 could be influenced by $\mathrm{C} / \mathrm{EBP} \alpha, \mathrm{H} 1299$ cells were transfected with $\mathrm{C} / \mathrm{EBP} \alpha$ expression vector, while Hela cells were transfected with si-C/EBP $\alpha$. First, the overexpression and knockdown of $\mathrm{C} / \mathrm{EBP} \alpha$ were confirmed

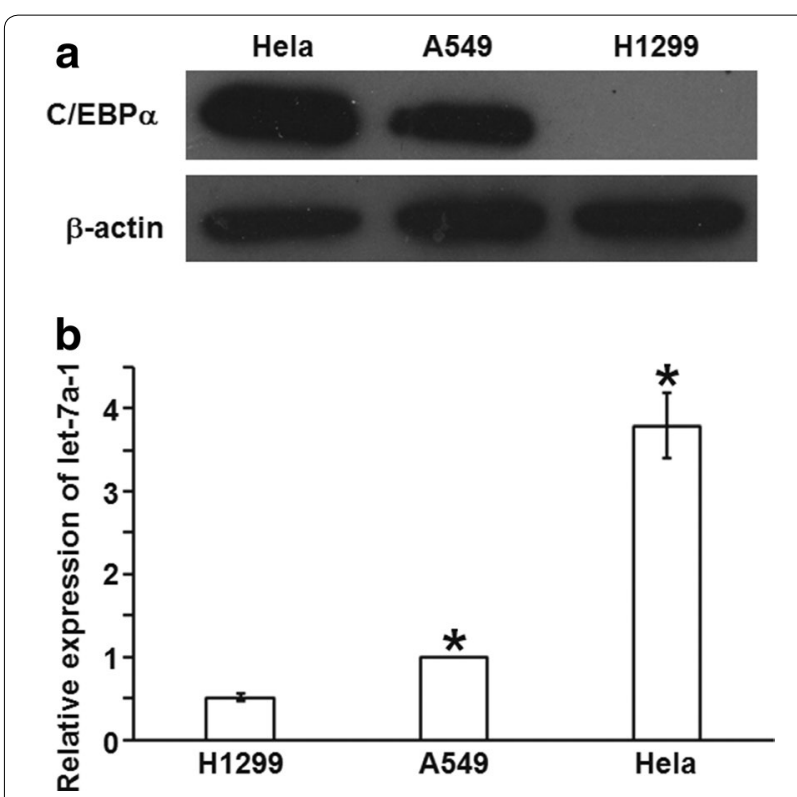

Fig. 1 Expression of C/EBPa and let-7a-1. Detection of (a) C/EBPa protein $(30 \mu \mathrm{g})$ expression and (b) let-7a-1 was performed by western blotting and quantitative real-time polymerase chain reaction, respectively, in Hela, A549 and H1299 cells. Data are represented as means \pm standard deviations from three independent tests. ${ }^{*} P<0.05$

Table 3 Oligonucleotide sequences used for polymerase chain reaction primers in chromatin immunoprecipitation assay

\begin{tabular}{lll}
\hline Name & Sequences & Fragment lengths \\
\hline CEBP1/2 & Forward, 5'-ACAAACTTCACAGGTTGAGGGC-3' reverse, 5'-TAATAAACCAGTGATAATGAGTGTCTTC-3' \\
CEBP3 & Forward, 5'-CAGCCGTCAGCATTATTTGT-3' reverse, 5'-CGAAGATTATCTTTTAAGATAGGGA-3' \\
CEBP4 & Forward, 5'-GTAAAAGGTGGTGGTAAGAGGGT-3' reverse, 5'-ACATGCATAATCTATGCTGTGGTT-3' \\
\hline
\end{tabular}




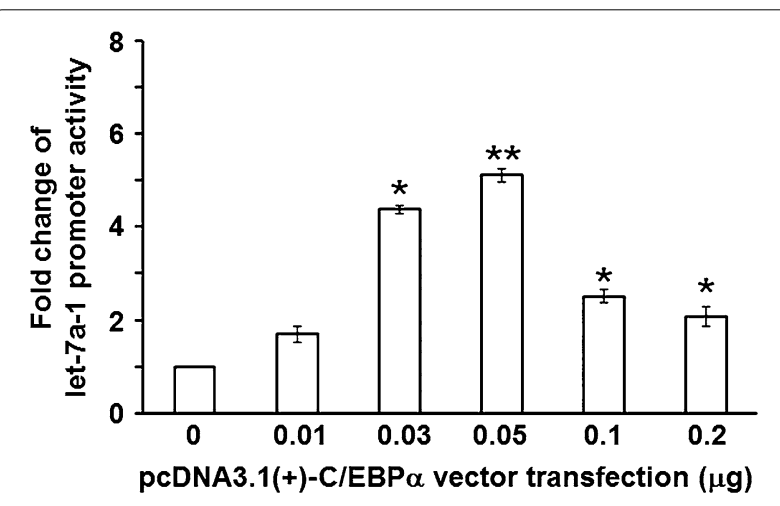

Fig. 2 Effect of ectopic C/EBPa expression on promoter activity of let-7a-1 in $\mathrm{H} 1299$ cells. Data are represented as means \pm standard deviations from three independent tests. ${ }^{*} P<0.05$; ${ }^{* *} P<0.005$

by western blotting analysis (Fig. 3a). In addition, overexpression of $\mathrm{C} / \mathrm{EBP} \alpha$ increased the expression level of pri-let-7a-1 by 3.97 -fold in $\mathrm{H} 1299$ cells (Fig. 3b), whereas knockdown of $\mathrm{C} / \mathrm{EBP} \alpha$ decreased the expression level of pri-let-7a-1 by about $50 \%$ in Hela cells (Fig. 3c). Meanwhile, luciferase reporter assay showed that ectopic expression of $\mathrm{C} / \mathrm{EBP} \alpha$ significantly reduced luciferase activity in $\mathrm{H} 1299$ cells transfected with pMIR7aT (Fig. 3d), while knockdown of $\mathrm{C} / \mathrm{EBP} \alpha$ significantly increased luciferase activity in Hela cells with si-C/EBP $\alpha$ transfection (Fig. 3e). These results suggest that C/EBP- $\alpha$ up-regulates the expression level of let-7a at transcription level.

\section{The let-7a-1 gene promoter contains potential binding sites for C/EBPa}

According to MatInspector with Matrix Similarity 0.85 and Matrix Family Library, there are four C/ EBP potential binding sites within $2.1 \mathrm{~kb}$ of human let7a-1 promoter upstream of the transcription start site. These four C/EBP potential binding sites were termed as CEBP $1 / 2 / 3 / 4$, where CEBP $1 / 2$ sites were in tandem within a 57-bp sequence $(-1726 /-1670)$ (Fig. 4a). After wild-type and mutant sequences of CEBP1/2/3/4 elements as well as $\mathrm{C} / \mathrm{EBP} \alpha$ consensus sequence (CEBPcw/ $\mathrm{cm}$ ) were synthesized and inserted into reporter gene vector, the constructs were used to investigate the function and importance of these $\mathrm{C} / \mathrm{EBP} \alpha$ binding sites for let-7a-1 gene expression using dual-luciferase reporter gene assay. All of the plasmid constructs were transiently co-transfected into $\mathrm{H} 1299$ cells with pcDNA3.1(+)-C/ $\mathrm{EBP} \alpha$, using pcDNA3.1(+) as control. Compared to cotransfection with pcDNA3.1(+), all wild-type C/EBP elements co-transfected with pcDNA3.1(+)-C/EBP $\alpha$ presented significantly increased luciferase activity. Moreover, the increase of C/EBP elements within let-7a-1 was higher than $\mathrm{C} / \mathrm{EBP}$ consensus. However, mutant C/EBP elements displayed insignificant change in luciferase activity in response to the ectopic expression of $\mathrm{C} / \mathrm{EBP} \alpha$ (Fig. 4b). These results indicate that let-7a-1 gene promoter contains potential binding sites for $\mathrm{C} / \mathrm{EBP} \alpha$.

\section{C/EBPa can bind let-7a-1 promoter as demonstrated by EMSA}

To determine whether these putative C/EBP elements are capable of binding transcription factor $\mathrm{C} / \mathrm{EBP} \alpha$ in vitro, we performed a series of EMSA experiments with nuclear extracts from $\mathrm{H} 1299$ cells with ectopic C/EBP $\alpha$ expression, using $\mathrm{C} / \mathrm{EBP}$ consensus sequence as positive control. All of the four CEBP probes and C/EBP consensus sequence showed transcription factor binding activity. Furthermore, these complexes were blocked specifically by anti-C/EBP $\alpha$ antibody and were effectively competed by cold competitor oligonucleotides (Fig. 5). The result suggests that $\mathrm{C} / \mathrm{EBP} \alpha$ can bind let-7a-1 promoter.

\section{The let-7a-1 promoter is a direct transcriptional target of $\mathrm{C} /$ EBPa as determined by ChIP assay}

In order to further confirm that $\mathrm{C} / \mathrm{EBP} \alpha$ indeed binds to let-7a-1 promoter, we performed endogenous ChIP. First, $\mathrm{C} / \mathrm{EBP} \alpha$ proteins were immunoprecipitated from DNA-protein cross-linked cell lysates. After the removal of all proteins, the recovered DNA was precipitated by ethanol and amplified by PCR using primers specific for let-7a-1 promoter. In contrast to H1299 cells transfected with pcDNA3.1(+), H1299 cells transfected with pcDNA3.1(+)-C/EBP $\alpha$ showed that all of four C/EBP sites within let-7a-1 promoter were indeed associated with $\mathrm{C} / \mathrm{EBP} \alpha$ immunoprecipitates (Fig. 6, lanes 4-6), whereas a IgG negative control failed to precipitate any let-7a-1 promoter DNA (Fig. 6, lanes 7-9). The result indicates that let-7a-1 promoter is a direct transcriptional target of $\mathrm{C} / \mathrm{EBP} \alpha$.

\section{Discussion}

miRNAs are a group of gene regulators that play important roles in biologic processes such as cell proliferation, differentiation, and apoptosis. The dysregulation of miRNAs is associated with the development of cancers, including lung cancer [5, 28, 29]. Many evidences have indicated that miRNA genes are transcribed by RNA polymerase II, and only a few miRNA promoters in $H$. sapiens have been identified so far. As class II genes, expressions of many miRNAs are also regulated by enhancers or hormones [30-32]. As a result, one of the reasons for the dysregulation of miRNAs in tumor tissues or cells may be the dysregulation at transcription level.

$\mathrm{C} / \mathrm{EBP} \alpha$ is a basic leucine zipper transcription factor that is expressed in many tissues, and plays an important role 


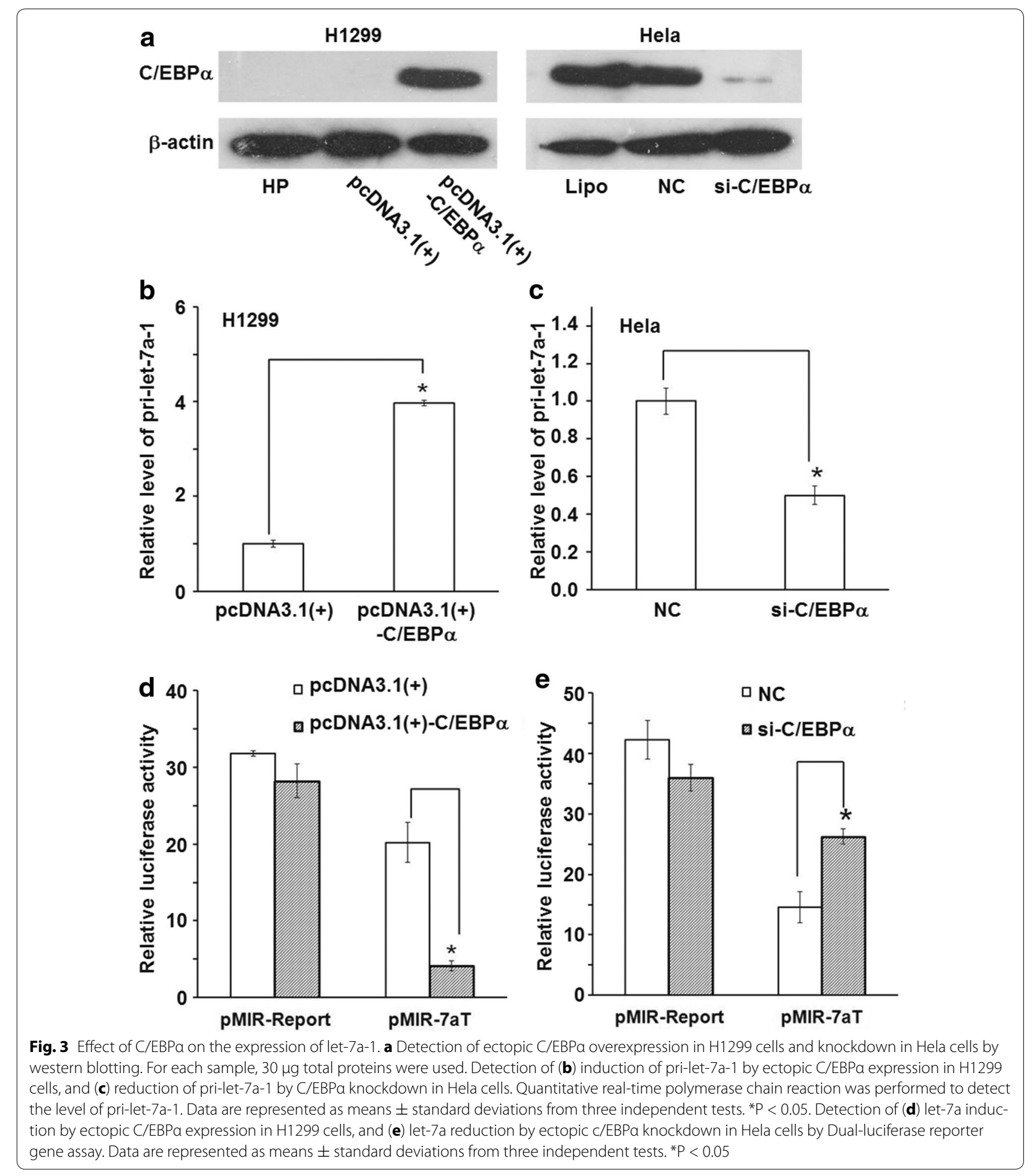

in regulating the balance between cell proliferation and cell differentiation $[17,33]$. Loss of C/EBP $\alpha$ functions has been linked to leukemogenesis, lung cancer, liver cancer, etc., suggesting an important role for $\mathrm{C} / \mathrm{EBP} \alpha$ as a tumor suppressor [34, 35]. A growing number of studies have demonstrated the regulation of specific miRNAs by $\mathrm{C} /$ EBPa. Fazi et al. first identify miR-223 as a direct target of $\mathrm{C} / \mathrm{EBP} \alpha$, and C/EBP $\alpha$-induced up-regulation of miR-223 


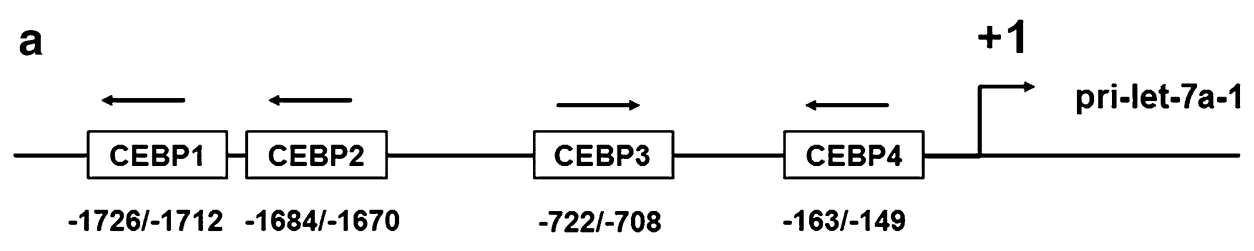

b

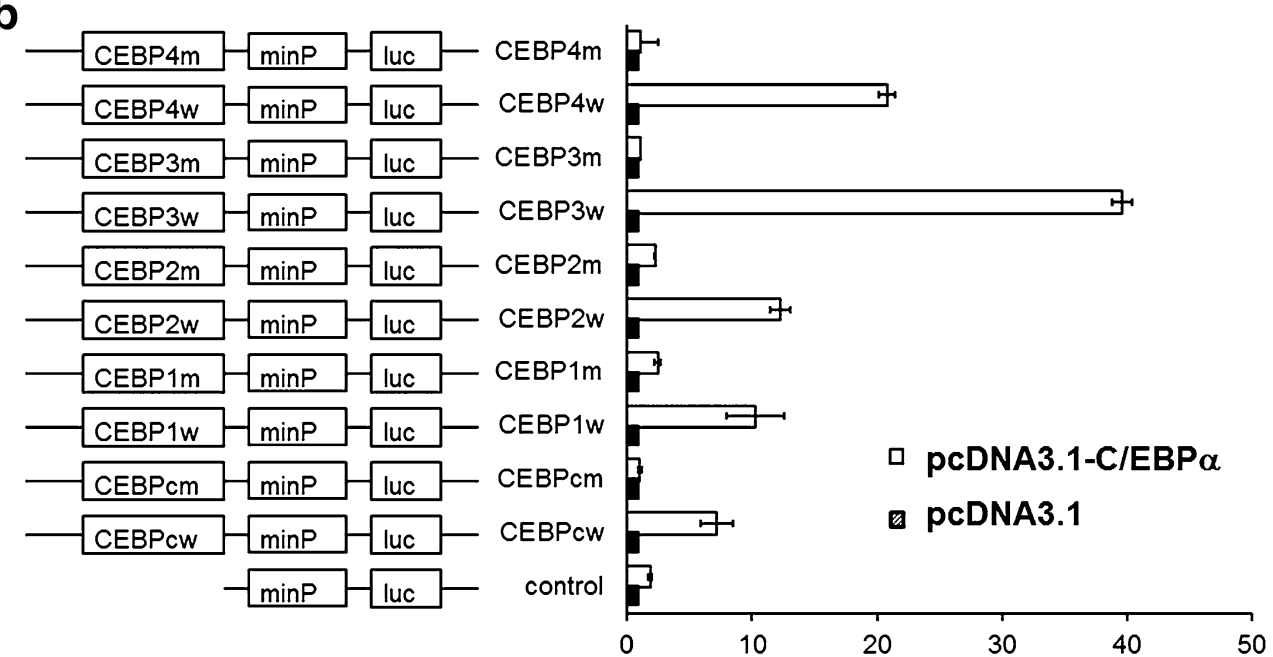

Fig. 4 Four potential binding sites for C/EBPa in let-7a-1 gene promoter. a Schematic representation of four examined putative C/EBP binding sites in the promoter region of let-7a-1 predicted by MatInspector software. $\mathbf{b}$ Detection of the functions of four putative C/EBP elements by reporter gene assay. After wild-type and mutant sequences of CEBP1/2/3/4 elements as well as C/EBPa consensus sequence (CEBPCw/Cm) were synthesized and inserted into reporter gene vector, the constructs were used to investigate the function and importance of these C/EBPa binding sites for let7a-1 gene expression using dual-luciferase reporter gene assay. All of the plasmid constructs were transiently co-transfected into H1299 cells with pcDNA3.1(+)-C/EBPa, using pcDNA3.1 (+) as control

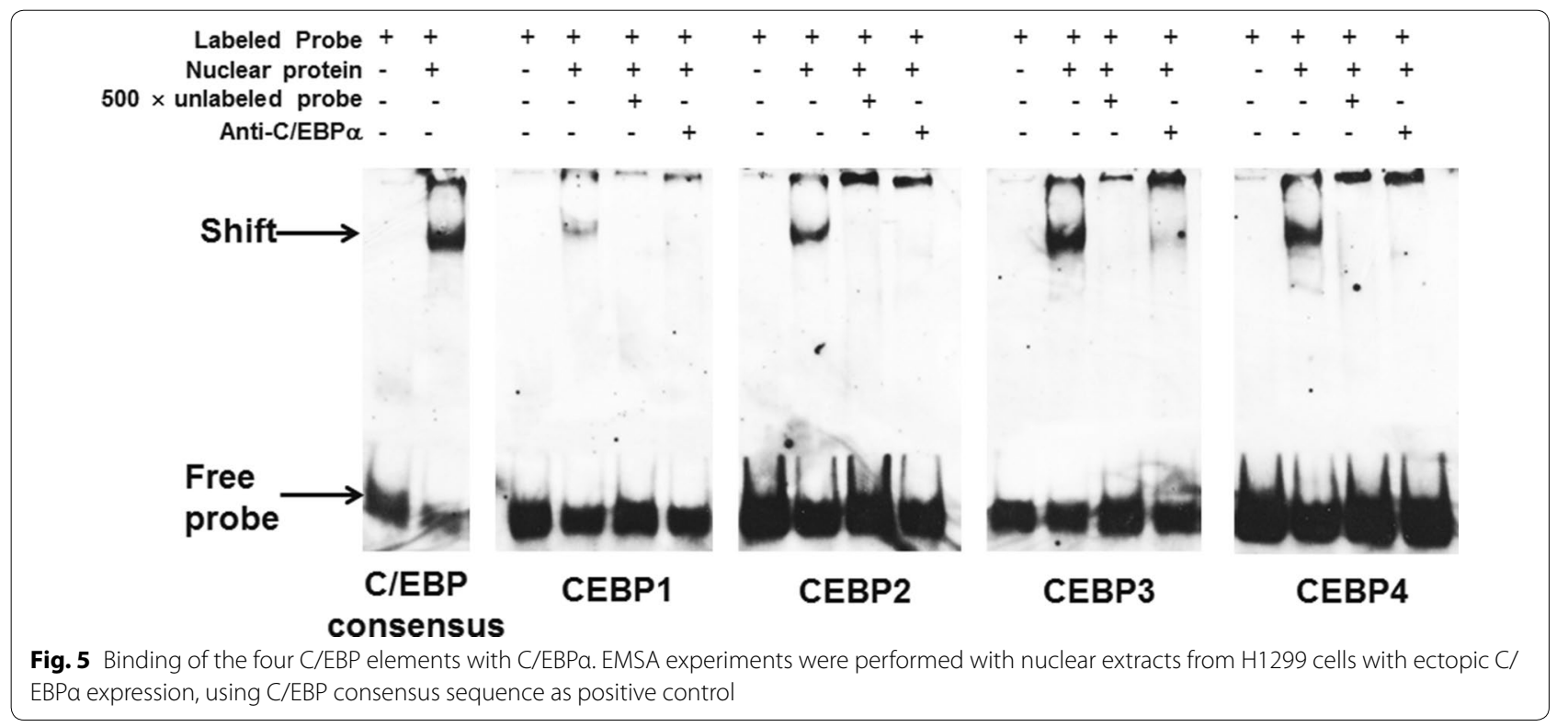

leads to granulopoiesis [19]. Zeng et al. report that C/ EBP $\alpha$ directly interacts with miR-122 (hepatocyte-specific miRNA) promoter and transactivates it [20]. Moreover, recent studies show that several tumor suppressor miRNAs are directly regulated by $\mathrm{C} / \mathrm{EBP} \alpha$, such as miR-223, miR34a and miR-30C, and that transactivation of all miRNAs 

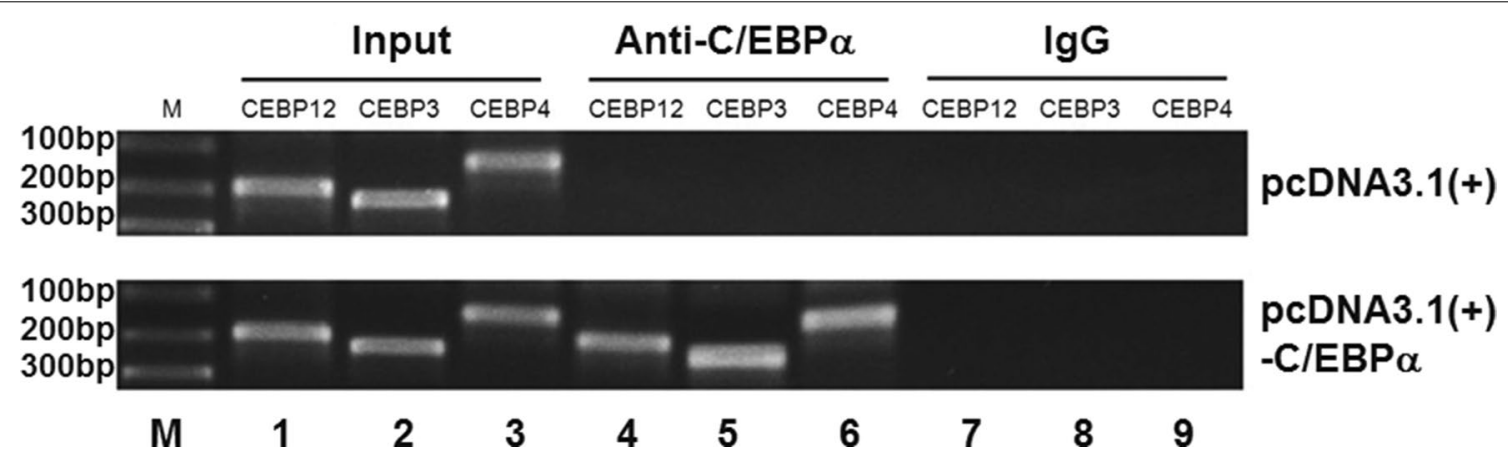

Fig. 6 Targeting of let-7a-1 promoter by C/EBPa. ChIP assay was performed on H1299 cells transfeted with pcDNA3.1(+) or pcDNA3.1(+)-C/EBPa. C/EBPa proteins were immunoprecipitated from DNA-protein cross-linked cell lysates. After the removal of all proteins, the recovered DNA was precipitated by ethanol and amplified by PCR using primers specific for let-7a-1 promoter

is inhibited along with the down-regulated expression of $\mathrm{C} / \mathrm{EBP} \alpha$ [21-23]. In A549 and H1299 lung cancer cells, ectopic $\mathrm{C} / \mathrm{EBP} \alpha$ expression increases the expression of miR-1 by 6.1 and 4.92-fold, respectively [24]. miR-661 is another C/EBP $\alpha$ target [25].

Our previous study shows that $\mathrm{C} / \mathrm{EBP} \alpha$ enhances the promoter activity of let-7a-1 gene in lung cancer A549 cells [18]. In the present study, we identify that let-7a-1 gene is another new target of C/EBP $\alpha$. We first examined the association between pri-let-7a-1 and C/EBP $\alpha$ expression. The expression levels of $\mathrm{C} / \mathrm{EBP} \alpha$ and prilet-7a-1 are found to be down-regulated in several lung cancer cell lines [5, 36], whereas Hela cells have high level of let-7 expression. Therefore, we selected lung cancer cell lines A549 and H1299, as well as and Hela cells to detect expression levels of the two by qRT-PCR and western blotting. The results show that pri-let-7a-1 level is positive correlated with $\mathrm{C} / \mathrm{EBP} \alpha$ expression. Furthermore, the ectopic expression of $\mathrm{C} / \mathrm{EBP} \alpha$ increases pri-let-7a-1 level in H1299 cells, while RNA interference for $\mathrm{C} / \mathrm{EBP} \alpha$ decreases pri-let-7a-1 level in Hela cells. The results demonstrate that $\mathrm{C} / \mathrm{EBP} \alpha$ transactivates the expression of let-7a-1 gene. Based on the fact that let$7 a-1$ is the most abundant specie of let-7a subfamily, reporter gene assay is performed to observe the effect of $\mathrm{C} / \mathrm{EBP} \alpha$ on mature-let-7a expression. Dual-luciferase detection shows that ectopic expression of $\mathrm{C} / \mathrm{EBP} \alpha$ increases mature-let-7a level in $\mathrm{H} 1299$ cells, while RNA interference for $\mathrm{C} / \mathrm{EBP} \alpha$ decreases mature-let-7a level in Hela cells. Moreover, reporter gene assay performed in $\mathrm{H} 1299$ cells has displayed that ectopic expression of $\mathrm{C} / \mathrm{EBP} \alpha$ increases promoter activity of let-7a-1, being in accordance with our previous result [18]. Therefore, the transcription factor $\mathrm{C} / \mathrm{EBP} \alpha$ can up-regulate the expression of let-7a-1 gene at transcription level.
Bioinformatics assay has identified four putative $\mathrm{C} /$ EBP elements within let-7a-1 promoter. We infer that at least one of them may mediate the transactivation effect of $\mathrm{C} / \mathrm{EBP} \alpha$. To confirm this, luciferase activity assay was performed in H1299 cells to analyze the function of the four putative CEBP elements. The results showedthat all of the four elements respond to ectopic expression of $\mathrm{C}$ / $\mathrm{EBP} \alpha$, and their luciferase activities are higher than that of $\mathrm{C} / \mathrm{EBP}$ consensus sequence used as positive control. Among them, CEBP3 element has displayed the highest activity. Furthermore, in vitro binding assay shows that all of the four C/EBP elements and C/EBP consensus sequence have binding capacity with nuclear protein extracted from $\mathrm{H} 1299$ cells with ectopic C/EBP $\alpha$ expression. In addition, these binding complexes can be blocked by anti-C/EBP $\alpha$ antibody specifically. At last, ChIP assay demonstrates the direct interaction between $\mathrm{C} / \mathrm{EBP} \alpha$ and the four C/EBP elements. In summary, the present study identifies tumor suppressor miRNA let-7a-1 gene as a new direct target of transcription factor C/EBP $\alpha$. Our results conclude that decrease or absence of tumor suppressor $\mathrm{C} / \mathrm{EBP} \alpha$ contributes to the transcriptional inhibition of let-7a-1.

\section{Author details}

${ }^{1}$ Department of Biochemistry and Molecular Biology, School of Medicine, Shandong University, Jinan 250012, People's Republic of China. ${ }^{2}$ Department of Thoracic Surgery, Qilu Hospital, Shandong University, No. 107 Wenhuaxi Road, Jinan 250012, Shandong, People's Republic of China.

\section{Acknowledgements}

This work was supported by grants from the National Natural Science Foundation of China (No. 81372764) and the Natural Science Foundation of Shandong Province (No. ZR2015HM047).

\section{Competing interests}

All authors declare that they have no competing interests.

Received: 1 January 2016 Accepted: 3 March 2016 Published online: 09 March 2016 


\section{References}

1. Boyerinas B, Park SM, Hau A, Murmann AE, Peter ME. The role of let-7 in cell differentiation and cancer. Endocr Relat Cancer. 2010;17(1):F19-36.

2. Johnson SM, Grosshans H, Shingara J, Byrom M, Jarvis R, Cheng A, Labourier E, Reinert KL, Brown D, Slack FJ. RAS is regulated by the let-7 microRNA family. Cell. 2005;120(5):635-47.

3. Lee YS, Dutta A. The tumor suppressor microRNA let-7 represses the HMGA2 oncogene. Genes Dev. 2007;21(9):1025-30.

4. Sampson VB, Rong NH, Han J, Yang Q, Aris V, Soteropoulos P, Petrelli NJ, Dunn SP, Krueger LJ. MicroRNA let-7a down-regulates MYC and reverts MYC-induced growth in Burkitt lymphoma cells. Cancer Res. 2007;67(20):9762-70.

5. Takamizawa J, Konishi H, Yanagisawa K, Tomida S, Osada H, Endoh H, Harano T, Yatabe Y, Nagino M, Nimura Y, et al. Reduced expression of the let-7 microRNAs in human lung cancers in association with shortened postoperative survival. Cancer Res. 2004;64(11):3753-6.

6. Akao Y, Nakagawa Y, Naoe T. let-7 microRNA functions as a potential growth suppressor in human colon cancer cells. Biol Pharm Bull. 2006;29(5):903-6.

7. Dahiya N, Sherman-Baust CA, Wang TL, Davidson B, Shih le M, Zhang Y, Wood W, Becker KG, Morin PJ. MicroRNA expression and identification of putative miRNA targets in ovarian cancer. PLoS ONE. 2008;3(6):e2436.

8. Roush S, Slack FJ. The let-7 family of microRNAs. Trends Cell Biol. 2008;18(10):505-16

9. Chang TC, Yu D, Lee YS, Wentzel EA, Arking DE, West KM, Dang CV, Thomas-Tikhonenko A, Mendell JT. Widespread microRNA repression by Myc contributes to tumorigenesis. Nat Genet. 2008;40(1):43-50.

10. Wang Z, Lin S, Li JJ, Xu Z, Yao H, Zhu X, Xie D, Shen Z, Sze J, Li K, et al. MYC protein inhibits transcription of the microRNA cluster MC-let-7a-1 let-7d via noncanonical E-box. J Biol Chem. 2011;286(46):39703-14.

11. Mitra D, Das PM, Huynh FC, Jones FE. Jumonji/ARID1 B (JARID1B) protein promotes breast tumor cell cycle progression through epigenetic repression of microRNA let-7e. J Biol Chem. 2011;286(47):40531-5.

12. Wang DJ, Legesse-Miller A, Johnson EL, Coller HA. Regulation of the let7a-3 promoter by NF-kappaB. PLoS ONE. 2012;7(2):e31240.

13. Newman MA, Thomson JM, Hammond SM. Lin-28 interaction with the Let-7 precursor loop mediates regulated microRNA processing. RNA. 2008;14(8):1539-49.

14. Piskounova E, Viswanathan SR, Janas M, LaPierre RJ, Daley GQ, Sliz P, Gregory RI. Determinants of microRNA processing inhibition by the developmentally regulated RNA-binding protein Lin28. J Biol Chem. 2008;283(31):21310-4

15. Landgraf $P$, Rusu M, Sheridan R, Sewer A, lovino N, Aravin A, Pfeffer S, Rice A, Kamphorst AO, Landthaler M, et al. A mammalian microRNA expression atlas based on small RNA library sequencing. Cell. 2007;129(7):1401-14.

16. Koschmieder S, Halmos B, Levantini E, Tenen DG. Dysregulation of the C/EBPalpha differentiation pathway in human cancer. J Clin Oncol. 2009;27(4):619-28.

17. Schuster MB, Porse BT. C/EBPalpha: a tumour suppressor in multiple tissues? Biochim Biophys Acta. 2006;1766(1):88-103.

18. Zhao J, Ni N, Liu C, Zhang P, Yu Y. Cloning and characterization of the $5^{\prime}$ flanking region of microRNA let-7a-1/let-7f-1 gene cluster in human lung cancer cell. Afr J Biotechnol. 2011;10(46):9233-41.

19. Fazi F, Rosa A, Fatica A, Gelmetti V, De Marchis ML, Nervi C, Bozzoni I. A minicircuitry comprised of microRNA-223 and transcription factors NFI-A and C/EBPalpha regulates human granulopoiesis. Cell. 2005;123(5):819-31.

20. Zeng C, Wang R, Li D, Lin XJ, Wei QK, Yuan Y, Wang Q, Chen W, Zhuang SM. A novel GSK-3 beta-C/EBP alpha-miR-122-insulin-like growth factor receptor regulatory circuitry in human hepatocellular carcinoma. Hepatology. 2010;52(5):1702-12.
21. Pulikkan JA, Dengler V, Peramangalam PS, Peer Zada AA, Muller-Tidow C, Bohlander SK, Tenen DG, Behre G. Cell-cycle regulator E2F1 and microRNA-223 comprise an autoregulatory negative feedback loop in acute myeloid leukemia. Blood. 2010;115(9):1768-78.

22. Pulikkan JA, Peramangalam PS, Dengler $V$, Ho PA, Preudhomme $C$, Meshinchi S, Christopeit M, Nibourel O, Muller-Tidow C, Bohlander SK, et al. C/EBPalpha regulated microRNA-34a targets E2F3 during granulopoiesis and is down-regulated in AML with CEBPA mutations. Blood. 2010;116(25):5638-49.

23. Katzerke C, Madan V, Gerloff D, Brauer-Hartmann D, Hartmann JU, Wurm AA, Muller-Tidow C, Schnittger S, Tenen DG, Niederwieser D, et al. Transcription factor C/EBPalpha-induced microRNA-30c inactivates Notch1 during granulopoiesis and is downregulated in acute myeloid leukemia. Blood. 2013;122(14):2433-42.

24. Nasser MW, Datta J, Nuovo G, Kutay H, Motiwala T, Majumder S, Wang B, Suster S, Jacob ST, Ghoshal K. Down-regulation of micro-RNA-1 (miR-1) in lung cancer. Suppression of tumorigenic property of lung cancer cells and their sensitization to doxorubicin-induced apoptosis by miR-1. J Biol Chem. 2008;283(48):33394-405.

25. Reddy SD, Pakala SB, Ohshiro K, Rayala SK, Kumar R. MicroRNA-661, a c/ EBPalpha target, inhibits metastatic tumor antigen 1 and regulates its functions. Cancer Res. 2009;69(14):5639-42.

26. Cartharius K, Frech K, Grote K, Klocke B, Haltmeier M, Klingenhoff A, Frisch M, Bayerlein M, Werner T. MatInspector and beyond: promoter analysis based on transcription factor binding sites. Bioinformatics. 2005;21(13):2933-42.

27. Liu W, Zhang P, Chen W, Yu C, Cui F, Kong F, Zhang J, Jiang A. Characterization of two functional NKX3.1 binding sites upstream of the PCAN1 gene that are involved in the positive regulation of PCAN1 gene transcription. BMC Mol Biol. 2008;9:45

28. Lu J, Getz G, Miska EA, Alvarez-Saavedra E, Lamb J, Peck D, Sweet-Cordero A, Ebert BL, Mak RH, Ferrando AA, et al. MicroRNA expression profiles classify human cancers. Nature. 2005;435(7043):834-8.

29. Cho WC. MicroRNAs: potential biomarkers for cancer diagnosis, prognosis and targets for therapy. Int J Biochem Cell Biol. 2010;42(8):1273-81.

30. Lagos-Quintana M, Rauhut R, Lendeckel W, Tuschl T. Identification of novel genes coding for small expressed RNAs. Science. 2001;294(5543):853-8.

31. Johnson SM, Lin SY, Slack FJ. The time of appearance of the C. elegans let-7 microRNA is transcriptionally controlled utilizing a temporal regulatory element in its promoter. Dev Biol. 2003;259(2):364-79.

32. Lee Y, Jeon K, Lee JT, Kim S, Kim VN. MicroRNA maturation: stepwise processing and subcellular localization. EMBO J. 2002;21(17):4663-70.

33. Ramji DP, Foka P. CCAAT/enhancer-binding proteins: structure, function and regulation. Biochem J. 2002;365(Pt 3):561-75.

34. Gombart AF, Hofmann WK, Kawano S, Takeuchi S, Krug U, Kwok SH, Larsen RJ, Asou H, Miller CW, Hoelzer D, et al. Mutations in the gene encoding the transcription factor CCAAT/enhancer binding protein alpha in myelodysplastic syndromes and acute myeloid leukemias. Blood. 2002;99(4):1332-40.

35. Costa DB, Li S, Kocher O, Feins RH, Keller SM, Schiller JH, Johnson DH, Tenen DG, Halmos B. Immunohistochemical analysis of C/EBPalpha in non-small cell lung cancer reveals frequent down-regulation in stage II and IIIA tumors: a correlative study of E3590. Lung Cancer. 2007:56(1):97-103.

36. Halmos B, Huettner CS, Kocher O, Ferenczi K, Karp DD, Tenen DG. Downregulation and antiproliferative role of C/EBPalpha in lung cancer. Cancer Res. 2002;62(2):528-34. 